\section{International Scientific Journal Theoretical \& Applied Science}

p-ISSN: 2308-4944 (print) e-ISSN: 2409-0085 (online)

Year: 2017 Issue: 08 Volume: 52

Published: $30.08 .2017 \quad$ http://T-Science.org
Svetlana Ivanovna Izaak

$\mathrm{PhD}$, Professor of the Institute of Peace Civilizations, Moscow, Russia e-sepp@yandex.ru

Alexei Ivanovich Yudin

$\mathrm{PhD}$, assistant professor of the Institute of Peace Civilizations, Moscow, Russia

SECTION 19. Management. Marketing. Public administration.

\title{
MODELING A PERSONAL POTENTIAL OF THE INDUSTRIE SPORT
}

Abstract: The article shows that the development of sports industry, improving the competitiveness in the international arena is due, primarily human resources. In the study, the analysis of staffing of the sports industry. By means of regression analysis the models developed personnel potential in the sports industry with a high degree of reliability and prognostic value. Models allow to predict the need of sports organizations in frames.

Key words: human resources, sports industry, modeling, and regression analysis.

Language: Russian

Citation: Izaak SI, Yudin AI (2017) MODELING A PERSONAL POTENTIAL OF THE INDUSTRIE SPORT. ISJ Theoretical \& Applied Science, 08 (52): 95-101.

Soi: http://s-o-i.org/1.1/TAS-08-52-15 Doi: crossef https://dx.doi.org/10.15863/TAS.2017.08.52.15

\section{МОДЕЛИРОВАНИЕ КАДРОВОГО ПОТЕНЦИАЛА ИНДУСТРИИ СПОРТА}

Аннотация: В статье показано, что развитие индустрии спорта, повышение конкурентоспособности на международной арене обуславливается, в первую очередь, трудовыми ресурсами. В ходе исследования проведен анализ кадрового обеспечения спортивной отрасли. Посредством прочедуры регрессионного анализа разработаны модели кадрового потенциала спортивной отрасли, обладающие высокой степенью достоверности и прогностической значимости. Модели позволяют прогнозировать потребность физкультурно-спортивных организаций в кадрах.

Ключевые слова: кадровый потеничиал, индустрия спорта, моделирование, регрессионный анализ.

\section{Introduction}

Спорт в современном мире стал неотъемлемой частью международных отношений [12]. Спортивная деятельность способствует обеспечению национальных интересов и реализации стратегических национальных приоритетов России; упрочению позиций России на международной арене как одного из влиятельных центров современного мира $[10,11]$. Развитие индустрии спорта, повышение конкурентоспособности на международной арене обуславливается, в первую очередь, трудовыми ресурсами.

Анализ кадрового потенциала в области физической культуры и спорта на современном этапе общественного развития следует проводить в тесной взаимосвязи с финансовым, нормативноправовым, научно-техническим и др. потенциалами, которые оказывают существенной влияние на количественные и качественные характеристики кадрового обеспечения, закономерности его развития и эффективного использования [8, 14].

Моделирование, как направление формализации закономерностей развития спортивной индустрии, активно применяется в различных направлениях [4, 1]. Немаловажное значение в процессе разработки моделей отводится качественной статистической обработке медико-биологической, психофизиологической, педагогической, управленческой информации $\quad[13,9,7]$. Качественное проведение статистической обработки спортивной информации требует использования большого объема сложных и трудоемких математических расчетов, а также работы с различными по своей структуре показателями $[5,6]$. Разработка моделей кадрового обеспечения отрасли проводится на основе изучения массивов данных и анализа кадрового потенциала. 


\section{Materials and Methods}

В кадровом менеджменте основополагающей категорией, характеризующей трудовые ресурсы организации, региона, страны, являются кадры. Это понятие включает в себя постоянный (штатный) состав работников различных профессионально-квалификационных групп, состоящих в трудовых отношениях с организациями независимо от их формы собственности, целевой направленности, отраслевой принадлежности. Кадры можно классифицировать по основным сферам организации общества и основным уровням управления (рис. 1).

Кадровый потенциал в спортивной отрасли включает не только кадры, но и уровень их совместных возможностей, направленных на достижение уставных целей организации с наименьшими затратами труда и ресурсов [3]. Кадровый потенциал отражает ресурсный аспект развития организации, региона, страны. Кадровый потенциал заложен в тех функциях, которые исполняют квалифицированные, специально подготовленные для той или иной деятельности работники, и в силу своих способностей, квалификации, знаний опыта могут обеспечить эффективное функционирование организации. Развитие спортивной индустрии обеспечивается, прежде всего, кадровым обеспечением отрасли [2].

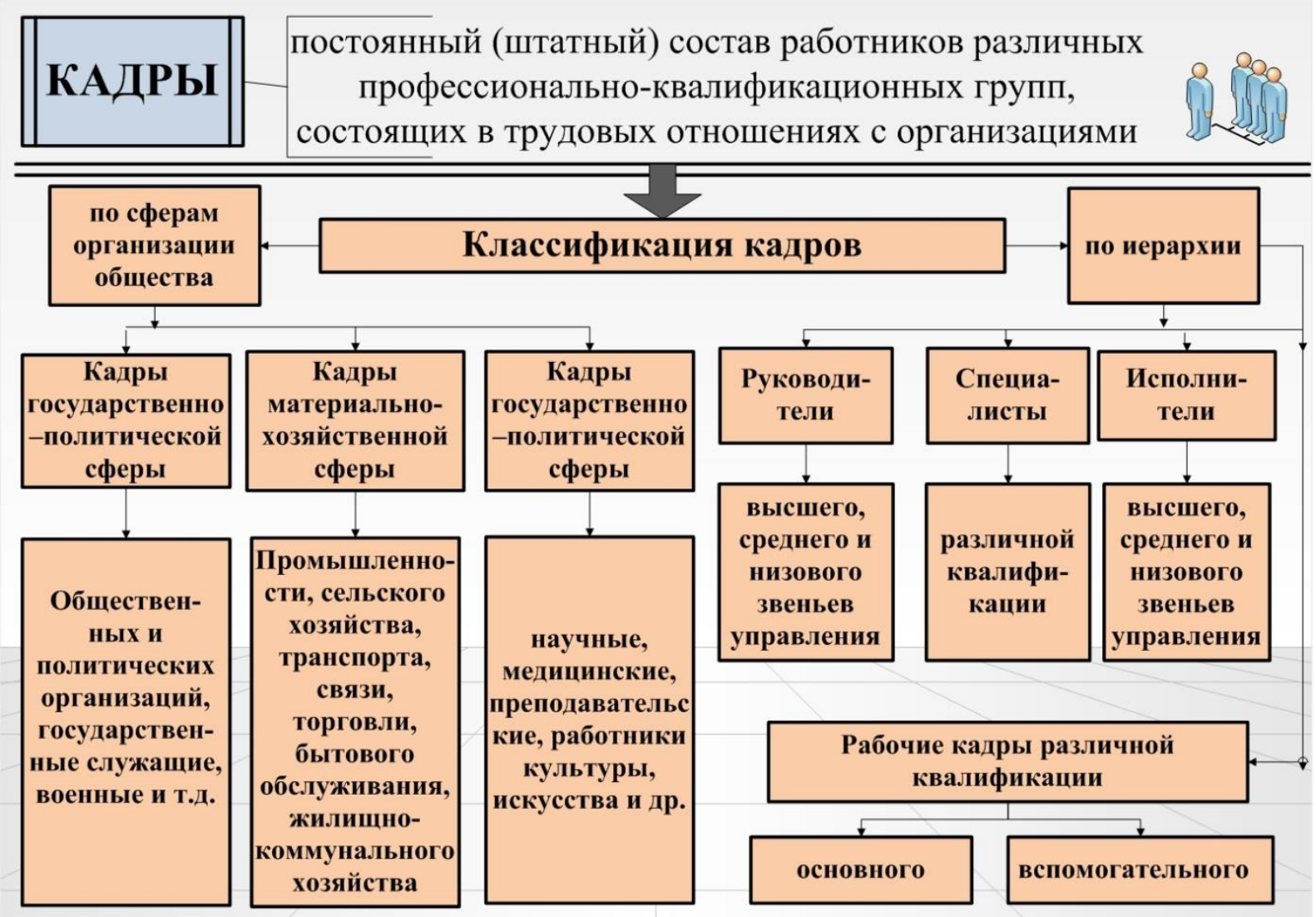

Рисунок 1 - Классификация кадров по основным сферам организации общества и основным уровням управления.

В ходе исследования проведен анализ положения, существующего в области кадрового обеспечения спортивной отрасли. Анализ осуществлялся по материалам федерального статистического наблюдения № 1-ФК «Сведения о физической культуре и спорте (региональный и федеральный аспект) за 2015-2016 гг.

В 2016 году количество штатных работников физкультурно-спортивных организаций, осуществляющих физкультурноспортивную, педагогическую административную работу, увеличилось на 2\% по сравнению с предыдущим отчетным периодом (в 2015 году - 361741 человек) и составило 368644 человек. В возрастном аспекте наблюдаются следующие тенденции: увеличение численности работников возрастной группы до 30 лет на 2\% (с 95659 в 2015 году до 97706 в 2016 году); рост численности работников возрастной группы до 31-60 лет на $1 \% \quad(236850 \quad$ и 240284 соответственно); возрастание значения 
показателя на 5\% в возрастной категории старше 60 лет (29232 и 30654 соответственно).

В зависимости от вида образовательной организации кадровый потенциал варьирует от 86223 и 25439 человек в общеобразовательных и дошкольных образовательных учреждениях до 17461 и 11911 человек в организациях высшего и среднего профессионального образования (по данным 2016 года). Кадровый потенциал спортивной сферы включает также следующие кадры, имеющие установленную законодательством профессиональную квалификацию (по данным 2016 года):

- работников организаций дополнительного образования детей, осуществляющих работу по физической культуре и спорту (105209 человек);

- работников физической культуры и спорта предприятий, организаций и учреждений (24452 человек);

- работников физической культуры и спорта спортивных сооружений (26591 человек);

- работников физической культуры и спорта фитнес-клубов (25448 человек);

- работники физической культуры и спорта по месту жительства (14844 человек);

- работников физической культуры и спорта аппаратов физкультурно-спортивных организаций всех уровней (5984 человек);

- работников физической культуры и спорта органов управления физической культурой и спортом всех уровней (7342 человек).

С учетом анализа кадрового потенциала спортивной отрасли проведено построение и изучение моделей его развития.

Моделирование связано с выяснением и воспроизведением свойств реального объекта или процесса с помощью математического описания. Необходимость моделирования связана со сложностью реальных объектов, на которые влияет большое количество различных причин. Построенные модели позволяют изучить сущность объекта или процесса и прогнозировать развитие.

Модель - упрощенное подобие объекта, которое воспроизводит его рассматриваемые свойства и характеристики. Наряду с физическими, графическими, семантическими моделями широко используются статистические модели, которые разработаны в настоящем исследовании.

С целью изучения зависимостей показателей кадрового обеспечения и расчета потребностей в кадрах разработаны регрессионные модели, позволяющие рассчитать значение одного (зависимого) показателя ( $\left.\mathrm{Y}_{\mathrm{i}}\right)$ при изменении значения другого (независимого) показателя $\left(\mathrm{X}_{\mathrm{i}}\right)$. Модели построены на массиве статистических данных, в качестве объектов которого - значения показателей кадрового потенциала спортивной индустрии 85 субъектов Российской Федерации (форма № 1-ФК за 2015 год).

Одним из значимых целевых показателей развития физической культуры и спорта, определенным в Стратегии развития физической культуры и спорта до 2020 года, является «доля граждан Российской Федерации, систематически занимающихся физической культурой и спортом, В общей численности населения». В регрессионной модели в качестве независимых переменных были выбраны градации показателя численности занимающихся физической культурой и спортом (человек) $\left(\mathrm{X}_{\mathrm{i}}\right)$; в качестве зависимых переменных $\left(\mathrm{Y}_{\mathrm{i}}\right) \quad-$ градации показателя общей численности штатных работников физической культуры и спорта (табл. 1, рис. 2-3).

\section{Регрессионые модели кадрового обеспечения индустрии спорта $\left(\mathbf{Y}_{\mathrm{i}}=\mathbf{a}_{\mathbf{i}} \mathbf{X}_{\mathbf{i}}+\mathbf{b}_{\mathbf{i}}\right)$}

Таблица 1

\begin{tabular}{|c|c|c|c|c|c|}
\hline № & $\begin{array}{c}\text { ЗАВИСИМАЯ } \\
\text { ПЕРЕМЕННАЯ }\left(\mathrm{Y}_{\mathrm{i}}\right)\end{array}$ & $\begin{array}{c}\text { НЕЗАВИСИМАЯ } \\
\text { ПЕРЕМЕННАЯ }\left(\mathrm{X}_{\mathrm{i}}\right)\end{array}$ & $\begin{array}{c}\text { Регрессионные } \\
\text { модели } \\
\left(\mathbf{Y}_{\mathbf{i}}=\mathbf{a}_{\mathbf{i}} \mathbf{X}_{\mathbf{i}}+\mathbf{b}_{\mathbf{i}}\right)\end{array}$ & $\mathbf{R}^{2}$ & $\mathbf{F}$ \\
\hline 1. & $\begin{array}{l}\text { Общая } \\
\text { штатных } \quad \text { работниковость } \\
\text { физической культуры и } \\
\left.\text { спорта (человек) ( } \mathrm{Y}_{1}\right), \\
\text { в том числе: }\end{array}$ & $\begin{array}{l}\text { Численность } \\
\text { занимающихся } \\
\text { физической культурой } \\
\text { и спортом (человек) } \\
\text { (всего) (X } 1), \text { в том } \\
\text { числе: }\end{array}$ & $Y_{1}=0,008 X_{1}-64,982$ & 0,943 & 1387,1 \\
\hline 2. & $\begin{array}{l}\text { Работники дошкольных } \\
\text { образовательных } \\
\text { учреждений, } \\
\text { осуществляющих } \\
\text { работу по физической } \\
\text { культуре и спорту }\left(\mathrm{Y}_{2}\right)\end{array}$ & $\begin{array}{l}\text { Численность } \\
\text { занимающихся } \\
\text { дошкольных } \\
\text { образовательных } \\
\text { учреждениях }\left(\mathrm{X}_{2}\right)\end{array}$ & $Y_{2}=0,0061 X_{2}+36,437$ & 0,63 & 142,9 \\
\hline
\end{tabular}




\begin{tabular}{l|lrl|l|ll} 
& ISRA (India) & $=\mathbf{1 . 3 4 4}$ & SIS (USA) & $=\mathbf{0 . 9 1 2}$ & ICV (Poland) & $=\mathbf{6 . 6 3 0}$ \\
Impact Factor: & ISI (Dubai, UAE) $=\mathbf{0 . 8 2 9}$ & PUHL (Russia) $=\mathbf{0 . 2 0 7}$ & PIF (India) & $=\mathbf{1 . 9 4 0}$ \\
& GIF (Australia) & $\mathbf{0 . 5 6 4}$ & ESJI (KZ) & $=3.860$ & IBI (India) & $\mathbf{= 4 . 2 6 0}$ \\
& JIF & $\mathbf{1 . 5 0 0}$ & SJIF (Morocco) & $=\mathbf{2 . 0 3 1}$ & & \\
\hline
\end{tabular}

\begin{tabular}{|c|c|c|c|c|c|}
\hline 3. & $\begin{array}{l}\text { Работники } \\
\text { общеобразовательных } \\
\text { учреждений, } \\
\text { осуществляющие } \\
\text { работу по физической } \\
\text { культуре и спорту }\left(\mathrm{Y}_{3}\right)\end{array}$ & $\begin{array}{l}\text { Численность } \\
\text { занимающихся в } \\
\text { общеобразовательных } \\
\text { организациях }\left(\mathrm{X}_{3}\right)\end{array}$ & $Y_{3}=0,0069 X_{3}+274,32$ & 0,804 & 340,9 \\
\hline 4. & $\begin{array}{l}\text { Работники организаций } \\
\text { среднего } \\
\text { профессионального } \\
\text { образования, } \\
\text { осуществляющих } \\
\text { работу по физической } \\
\text { культуре и спорту }\left(\mathrm{Y}_{4}\right)\end{array}$ & $\begin{array}{l}\text { Численность } \\
\text { занимающихся } \\
\text { образовательных } \\
\text { организациях среднего } \\
\text { профессионального } \\
\text { образования }\left(\mathrm{X}_{4}\right)\end{array}$ & $\mathrm{Y}_{4}=0,0069 \mathrm{X}_{4}+15,984$ & 0,74 & 234,2 \\
\hline 5. & $\begin{array}{l}\text { Работники организаций } \\
\text { высшего образования, } \\
\text { осуществляющих } \\
\text { работу по физической } \\
\text { культуре и спорту }\left(\mathrm{Y}_{5}\right)\end{array}$ & $\begin{array}{l}\text { Численность } \\
\text { занимающихся } \\
\text { образовательных } \\
\text { организациях высшего } \\
\text { образования }\left(\mathrm{X}_{5}\right)\end{array}$ & $Y_{5}=0,0082 X_{5}+26,095$ & 0,935 & 1206,7 \\
\hline 6. & $\begin{array}{l}\text { Работники организаций } \\
\text { дополнительного } \\
\text { образования детей, } \\
\text { осуществляющих } \\
\text { работу по физической } \\
\text { культуре и спорту (Y6) }\end{array}$ & $\begin{array}{l}\text { Численность } \\
\text { занимающихся } \\
\text { организациях } \\
\text { дополнительного } \\
\text { образования детей }\left(\mathrm{X}_{6}\right)\end{array}$ & $Y_{6}=0,0194 X_{6}+246,14$ & 0,84 & 448,9 \\
\hline 7. & $\begin{array}{l}\text { Работники } \\
\text { клубов }\left(\mathrm{Y}_{7}\right)\end{array}$ & $\begin{array}{l}\text { Численность } \\
\text { занимающихся } \\
\text { фитнес-клубах }\left(\mathrm{X}_{7}\right)\end{array}$ & $Y_{7}=0,0063 X_{7}+4,4885$ & 0,97 & 2259,8 \\
\hline 8. & $\begin{array}{lrr}\text { Работники } & \text { по } & \text { месту } \\
\text { жительства }\left(\mathrm{Y}_{8}\right) & \end{array}$ & $\begin{array}{l}\text { Численность } \\
\text { занимающихся } \\
\text { учреждениях } \\
\text { организациях по месту } \\
\text { жительства }\left(\mathrm{X}_{8}\right) \\
\end{array}$ & $Y_{8}=0,0044 X_{8}-5,1852$ & 0,74 & 233,2 \\
\hline
\end{tabular}

Разработанные регрессионные модели имеют различную прогностическую значимость, определяемую с помощью коэффициента детерминации $\mathrm{R}^{2}$ и $\mathrm{F}$-критерия Фишера. 


\begin{tabular}{l|lrl|lll} 
& ISRA (India) & $=\mathbf{1 . 3 4 4}$ & SIS (USA) & $=\mathbf{0 . 9 1 2}$ & ICV (Poland) & $=\mathbf{6 . 6 3 0}$ \\
Impact Factor: & ISI (Dubai, UAE) $=\mathbf{0 . 8 2 9}$ & PUHЦ (Russia) & $=\mathbf{0 . 2 0 7}$ & PIF (India) & $=\mathbf{1 . 9 4 0}$ \\
& GIF (Australia) & $\mathbf{0 . 5 6 4}$ & ESJI (KZ) & $=\mathbf{3 . 8 6 0}$ & IBI (India) & $=\mathbf{4 . 2 6 0}$ \\
& JIF & $\mathbf{1 . 5 0 0}$ & SJIF (Morocco) & $\mathbf{2 . 0 3 1}$ & & \\
\hline
\end{tabular}

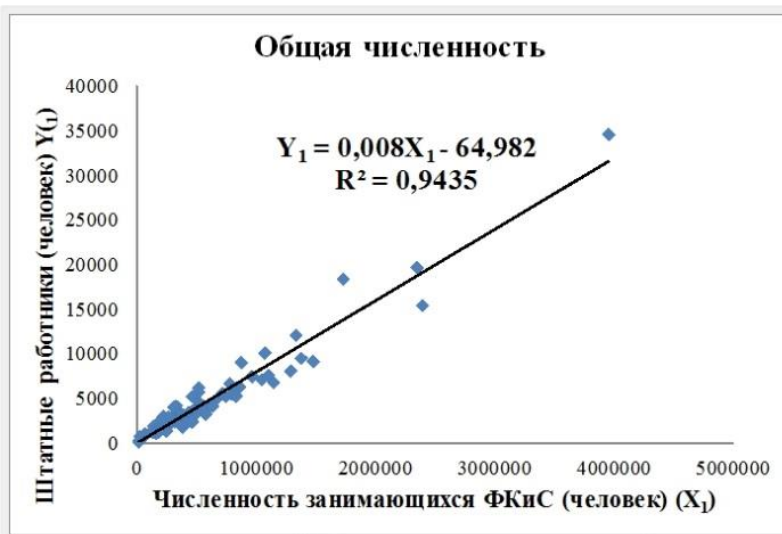

Общеобразовательные организации

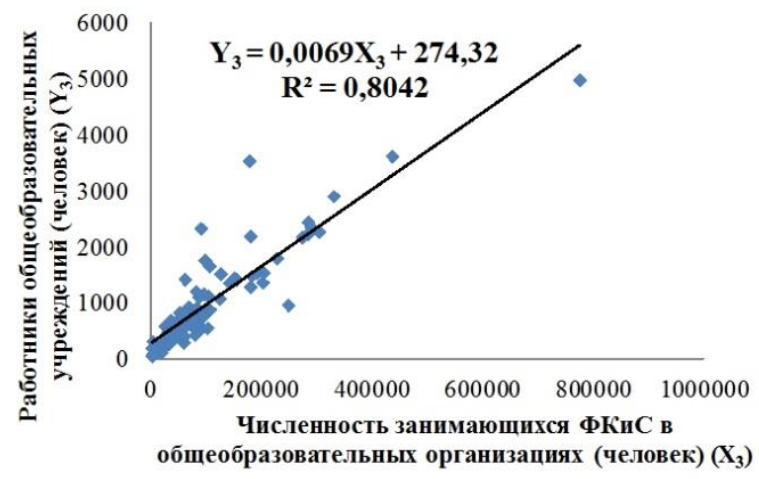

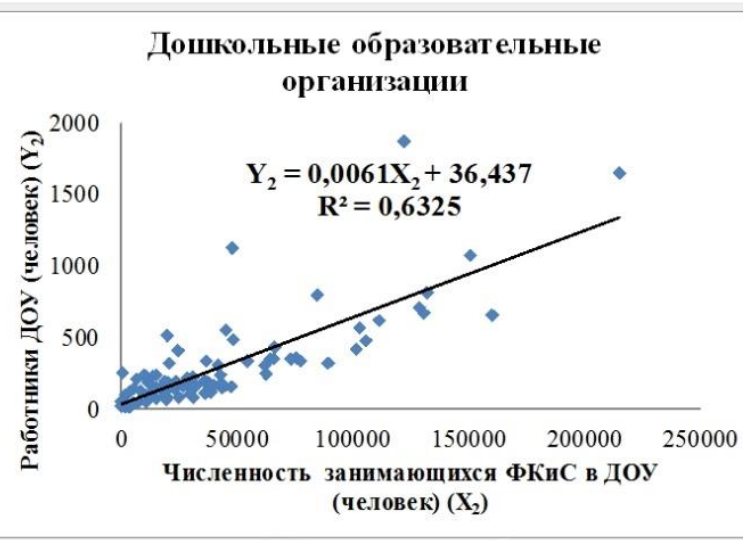

Организации СПО

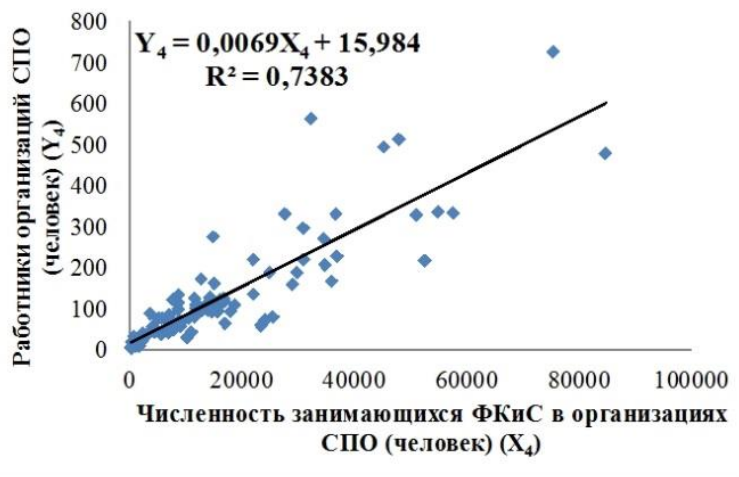

Рисунок 2 - Регрессионные модели кадрового обеспечения дошкольных образовательных организаций, общеобразовательных организаций и организаций среднего профессионального образования (СПО) с учетом численности занимающихся физической культурой и спортом (ФКиС) $\left(\mathbf{Y}_{1}-\mathbf{Y}_{4}\right)$.

Наибольшую достоверность имеет уравнение регрессии, в котором в качестве зависимой переменной определен показатель «работники фитнес-клубов» $\left(\mathrm{Y}_{7}\right)$, в качестве независимой переменной - «численность занимающихся в фитнес-клубах» $\left(\mathrm{X}_{7}\right)\left(\mathrm{R}^{2}=0,97\right)$.

Высокую достоверность имеет также модель для прогноза общей численности штатных работников $\left(\mathrm{Y}_{1}\right)$ в зависимости от числа занимающихся физической культурой и спортом, что позволяет прогнозировать в целом потребность в кадрах при увеличении численности занимающихся $\left(\mathrm{R}^{2}=0,943\right)$. Практически идентичными прогнозными свойствами обладает и модель кадрового обеспечения в сфере высшего образования $\left(\mathrm{R}^{2}\right.$ $=0,935$ ). 


\begin{tabular}{l|lrl|lll} 
& ISRA (India) & $=\mathbf{1 . 3 4 4}$ & SIS (USA) & $=\mathbf{0 . 9 1 2}$ & ICV (Poland) & $=\mathbf{6 . 6 3 0}$ \\
Impact Factor: & ISI (Dubai, UAE) $=\mathbf{0 . 8 2 9}$ & PUHЦ (Russia) & $=\mathbf{0 . 2 0 7}$ & PIF (India) & $=\mathbf{1 . 9 4 0}$ \\
& GIF (Australia) & $\mathbf{0 . 5 6 4}$ & ESJI (KZ) & $=\mathbf{3 . 8 6 0}$ & IBI (India) & $=\mathbf{4 . 2 6 0}$ \\
& JIF & $\mathbf{1 . 5 0 0}$ & SJIF (Morocco) & $\mathbf{2 . 0 3 1}$ & & \\
\hline
\end{tabular}
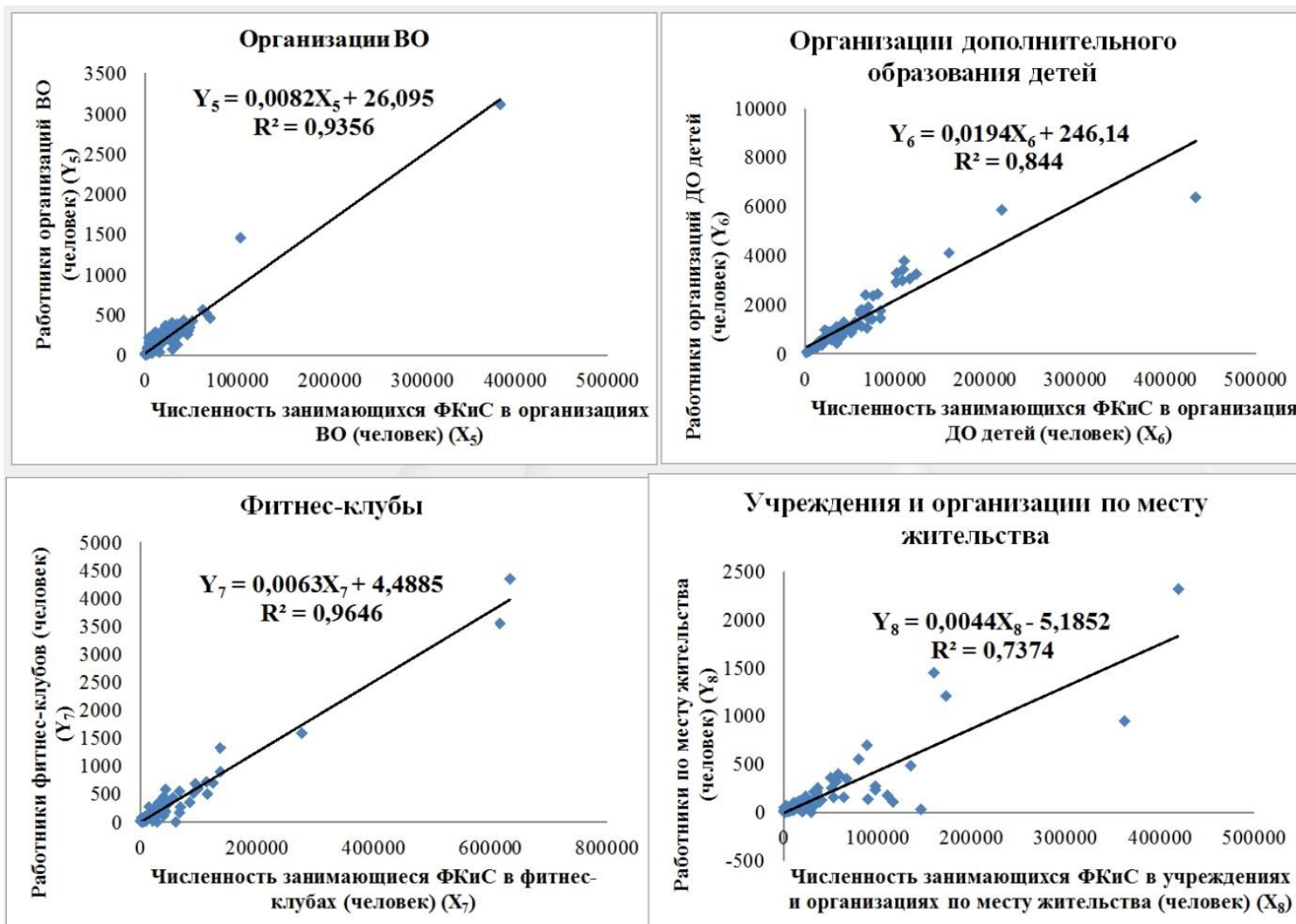

Учреждения и организации по месту жительства

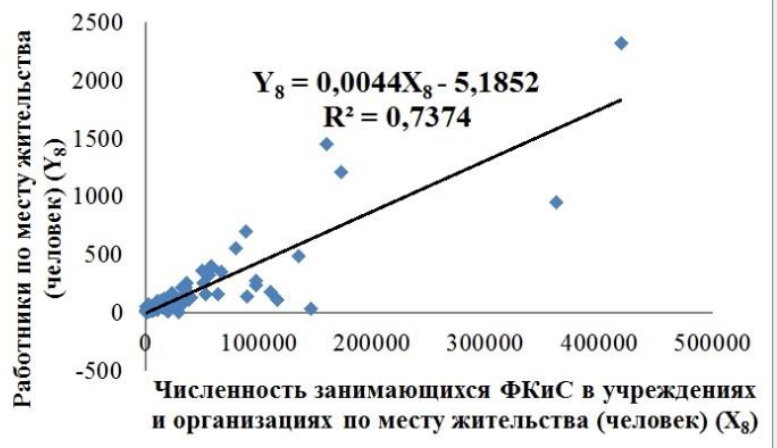

Рисунок 3 - Регрессионые модели кадрового обеспечения организаций высшего образования (ВО), организаций дополнительного образования детей, фитнес-клубов и учреждений и организаций по месту жительства с учетом численности занимающихся физической культурой и спортом (ФКиС) (Y5 - Y8).

\section{Conclusion}

1. В ходе исследования проведен анализ кадрового потенциала спортивной отрасли. Несмотря на неоднородность регионов России по темпам роста показателей в период с 2015 по 2016 гг., характеризующих развитие отраслевого кадрового обеспечения, наблюдается в целом стабильный рост численности штатных работников различных по виду деятельности физкультурно-спортивных организаций.

2. Моделирование кадрового потенциала индустрии спорта проводилось с помощью статистических методов посредством процедуры регрессионного анализа. Разработанные модели обладают высокой степенью достоверности, что подтверждается высокими показателями коэффициента детерминации $\mathrm{R}^{2}$ и $\mathrm{F}$-критерия Фишера. Наибольшую прогностическую значимость имеют модели развития кадрового обеспечения в фитнес-клубах, в высших учебных заведениях, а также всей отрасли в целом.

Разработанные модели позволяют прогнозировать потребность в кадрах при увеличении численности занимающихся.

\section{References:}

1. Izaak S.I. (1997) Statisticheskie modeli differencirovannoj ocenki dvigatel'nyh vozmozhnostej detej i molodezhi: Diss. ... kand. ped. nauk; VNIIFK. M., 1997. -184 p.

2. Izaak S.I. (2013) Kadrovoe obespechenie organizacionno-upravlencheskogo mehanizma realizacii sistemy monitoringa fizicheskogo sostojanija uchashhihsja obrazovatel'nyh uchrezhdenij: Sbornik nauchnyh trudov Mezhdun. nauch.-prakt. konf. «Prioritety i perspektivy fizicheskoj kul'tury i massovogo sporta v uslovijah industrial'no-innovacionnogo 


\begin{tabular}{|c|c|c|c|c|c|c|}
\hline Impact Factor: & $\begin{array}{l}\text { ISRA (India) } \\
\text { ISI (Dubai, UAE } \\
\text { GIF (Australia) } \\
\text { JIF }\end{array}$ & $\begin{array}{l}=1.344 \\
=0.829 \\
=0.564 \\
=1.500\end{array}$ & $\begin{array}{l}\text { SIS (USA) } \\
\text { PИНЦ (Russia } \\
\text { ESJI (KZ) } \\
\text { SJIF (Morocco }\end{array}$ & $\begin{array}{r}=\mathbf{0 . 9 1 2} \\
=\mathbf{0 . 2 3 4} \\
=\mathbf{3 . 8 6 0} \\
=\mathbf{2 . 0 3 1}\end{array}$ & $\begin{array}{l}\text { ICV (Poland) } \\
\text { PIF (India) } \\
\text { IBI (India) }\end{array}$ & $\begin{array}{l}=6.630 \\
=1.940 \\
=4.260\end{array}$ \\
\hline
\end{tabular}

razvitija» / Pod red. A.K. Kul'nazarova, S.I. Izaak i dr., Astana, Agentstvo Respubliki Kazahstan po delam sporta i fizicheskoj kul'tury: Izd-vo TOO «Djeme», 2013. p. 174182.

3. Izaak S.I. (2014) Analiz kadrovogo potenciala fizicheskoj kul'tury i sporta $\mathrm{v}$ praktike gosudarstvennogo i municipal'nogo upravlenija v Rossii: Sbornik statej Mezhdunarodnoj nauchno-prakticheskoj konferencii MIGSU RANHiGS pri Prezidente Rossijskoj Federacii «Jeffektivnoe gosudarstvennoe i municipal'noe upravlenie kak faktor social'nojekonomicheskogo razvitija Rossii». M.: Prospekt, 2014. p. $234-238$.

4. Izaak S.I. (2016) Ispol'zovanie statisticheskih metodov v obrabotke dannyh dlja kompleksnogo analiza mediko-biologicheskoj, psihofiziologicheskoj, pedagogicheskoj informacii: materialy Vserossijskoj nauchnoprakticheskoj konferencii po voprosam sportivnoj nauki v detsko-junosheskom sporte i sporte vysshih dostizhenij. M.: CSTiSK, 2016. p. 168-177.

5. Izaak S.I. (2016) Sostojanie fizicheskogo razvitija i fizicheskoj podgotovlennosti detej, podrostkov, molodezhi na osnove tehnologii populjacionnogo monitoringa (na primere Rossijskoj Federacii) // Izvestija VUZov Kyrgyzstana. 2016. №. 9. p. 153-156.

6. Izaak S.I., Panasjuk T.V., Indreeva A.M. (2007) Vozrastnaja dinamika fizicheskogo razvitija shkol'nikov Kabardino-Balkarii, prozhivajushhih na razlichnoj vysote nad urovnem morja // Gigiena i sanitarija. 2007. № 2. p. 50-51.

7. Izaak S.I., Piskova D.M. (2009) Faktornyj analiz v sistematizacii i strukturizacii informacii o biologicheskih obektah: Materialy mezhvuz.
Nauchno-prakticheskoj konferencii «Jekonomika, upravlenie i pravo». - M., 2009. Vyp. 14. p. 9-12.

8. Parshikova N.V. (2015) Menedzhment, pravo, normativy // Doshkol'naja i shkol'naja fizkul'tura. Fizkul'tura i sport. M.: Sovetskij Sport, 2015. p. 5-6.

9. Parshikova N.V., Izaak S.I. (2016) Razrabotka strategicheskogo prognoza razvitija fizicheskoj kul'tury i massovogo sporta na period do 2030 goda // Chelovecheskij kapital. 2016. № 4 (88). p. 10-12.

10. Parshikova N.V., Izaak S.I., Kovalenko G.V. (2017) Sport v mezhdunarodnoj sisteme koordinat: novye vyzovy i vozmozhnosti // Teorija i praktika fizicheskoj kul'tury. 2017. № 7. p. 94-96.

11. Parshikova N.V., Izaak S.I., Malic V.N. (2017) Strategicheskie prioritety gosudarstvennoj politiki v oblasti massovogo sporta // Uchenye zapiski Universiteta im. P.F. Lesgafta. 2017. № 6 (148). p. 167-171.

12. Pel'menev V.K., Izaak S.I., Nikitin N.S., et al. (2016) Organizacionnye osnovy fizicheskoj kul'tury, sporta i turizma: monografija. Kaliningrad: Izd-vo BFU im. I. Kanta, 2016. $304 \mathrm{p}$.

13. Son'kin V.D., Izaak S.I. (1996) Opredelenie konstitucional'noj prinadlezhnosti junoshej 1720 let metodom raspoznavanija obrazov // Teorija i praktika fizicheskoj kul'tury. M., 1996. 9. p. 40-44.

14. Shahraj S.M., Izaak S.I. (2013) Analiz realizacii Strategii razvitija fizicheskoj kul'tury i sporta $\mathrm{v}$ Rossijskoj Federacii na period do 2020 g. v regionah i municipal'nyh obrazovanijah // Sport: jekonomika, pravo, upravlenie. 2013. № 4. p. 11-14. 